\title{
Examining Potentials of Building M\&A Preparedness
}

\author{
Nilesh Vaniya, Peter Bernus and Ovidiu Noran \\ Centre of Enterprise Architecture Research and Management (CEARM), Griffith University, \\ 170 Kessels Road, Nathan, Queensland, Australia \\ \{N.Vaniya,P.Bernus,O.Noran\}@griffith.edu.au
}

Keywords: $\quad$ Mergers, Acquisitions, Post-merger Integration (PMI), M\&A Preparedness Building.

\begin{abstract}
Enterprises are systems of systems that continuously evolve during their lifespan, be it in a directed or emergent way. As enterprises are in fact socio-technical systems, this evolution may occur in one or more specific areas - such as the human / organizational, the technology and / or the Information System that integrates the activities performed by humans and machines (technology). This paper addresses a special type of change, brought about by enterprise mergers or acquisitions (M\&As). M\&As are an important strategic transformation instrument in the hands of management; however, literature reveals that an alarming high percentage of M\&As do not achieve their declared objectives. In this paper we attempt to a) demonstrate that the success of such strategic changes depends on several essential and largely overlooked factors, and b) outline a possible approach of building preparedness for M\&As), so as to improve the chances of success. This paper also presents a retrospective M\&A case analysis to demonstrate the types of potential problems that could have been effectively addressed by anticipatory transformation facilitated by the proposed preparedness building approach.
\end{abstract}

\section{INTRODUCTION}

Enterprises as socio-technical systems are subject to continuous evolution. In addition, enterprises are also required to permanently adapt so as to satisfy the dynamic requirements of the environment in which they operate. The purpose of the research reflected in this paper is to demonstrate the principles and use of a Mergers and Acquisitions (M\&A) Preparedness Building Methodology (MAPBM) built on Enterprise Architecture (EA) concepts in order to create and support strategically important transformational activities.

In order to demonstrate the use of EA in M\&As, firstly we summarize the approaches suggested in the literature in order to tackle the issues that cause failures in M\&As, the solutions attempted to address those issues and the current gaps in related theory and practice. Secondly, we summarise the proposed MAPBM which aims to support enterprises in acquiring the necessary systemic properties before merger/acquisition and thus build preparedness for the desired type of M\&A. Subsequently, we describe a merger case study and using the MAPBM we demonstrate how, with strategic intent, a multifaceted transformation of the participating organisations could have been performed so as to achieve a state where the organisation was ready to perform a strategically attractive merger. Finally, we summarise the results and outline future work.

\section{M\&A: PROBLEMS AND TYPICAL SOLUTIONS}

Kumar (2009) categorizes M\&As as: horizontal (also known as 'mergers of equals'), vertical (where two or more participants have different position in the supply chain), and conglomerate. In addition to this typology, there are other differentiating aspects when one considers the nature of an M\&A - e.g., is the deal forced or voluntary, do the original identities of the participants change as a result of the transaction, etc. Irrespective of the type, M\&As can deliver positive outcomes for the participants. Based on the goal and the type of the deal, Walter (2004, pg. 62-77) lists some major advantages achievable through M\&As: market extension, economies of scale, cost (or revenue) economies of scope, other operating efficiencies, etc.

Unfortunately, according to recent research (Rodriguez, 2008, p.65), while the rate of M\&As has 
increased in the recent past, the probability of achieving the above-mentioned potential benefits has dropped to less than half (Rodriguez 2008, p.65). The precise percentage of the deals that fail to achieve the declared synergies and desired levels of integration varies according to industry, but is generally agreed to be greater than $50 \%$ (Alaranta and Henningsson, 2008); (Mehta and Hirschheim, 2007); (Rodriguez, 2008). M\&A problems have been researched from different perspectives and viewpoints. Next, we summarise the findings of current literature, with the intent of categorising and highlighting major M\&A issues from an Information Systems (IS) researcher's perspective.

\subsection{M\&A Issues}

We reviewed a wide range of M\&A literature to identify typical issue types (or issue categories) that are believed to have significant impact on the outcome of M\&As. Major issues having the highest impact on M\&A success are claimed to be in the domains of IS and organizational integration (Larsen, 2005); (Mehta and Hirschheim, 2007); (Mo and Nemes, 2009); (Rodriguez 2008); (Schuler and Jackson 2001). Major M\&A issues have also been highlighted in (Baro et al., 2008); (Chatterjee, 2009); (Epstein, 2004); (Hwang, 2004); (Larsen, 2005); (McDonald et al., 2005); (Mehta and Hirschheim, 2007); (Rodriguez, 2008); (Stylianou et al., 1996); (Walsh, 1989). We identified three issue types illustrated below:

1) Business Management issues/concerns, regarding

- Merger motive, expectations and planning,

- Level of Coherency of Integration Strategy,

- IS/Information Technology (IT) Involvement in M\&A planning,

- Organisational integration management.

2) Human Resource (HR) issues, due to the

- Requirement of strong integration team, executive leadership,

- Need to consider not only general HR issues but the individual human side of M\&A,

- Need for top-down communication of vision, M\&A strategies, and of M\&A planning,

- Personnel concerns (such as benefits, retention and cut-offs),

- Lack of supporting programs, advanced notification, extended benefits, outplacement activities.

3) IT and IS issues, resulting from

- IT Attributes,
- IT Integration Management,

- Information and Communication Technology (ICT) vision,

- Enterprise Systems / Applications integration such as ERP, SCM, CRM, etc.,

- Data integration issues,

- Technical compatibility.

Thus, most issues in strategic transformations (and M\&As as a special case thereof) fall in three main categories: Business Management, Human / Organizational and IT / IS). Clearly, solving only one type of issues (e.g. HR) without considering the relationships with the other issue types would be less effective than expected or may be altogether ineffective. Hence for any enterprise-wide transformation methodology we must consider how to jointly solve these three types of issues.

Note that not all of the above issues can be addressed in detail during preparedness building in all circumstances. The ability to address such issues during preparedness building relies on the ability to sense their root causes as well as the ability to respond and control them.

\subsection{Existing Solutions}

Recent developments in M\&A research aimed to study the reasons of M\&A failures and improve their success rate. As discussed below, most of the studies focused on a single issue and proposed a solution to it without considering the relationship/effect of that solution on other issue types and sources. In our view, this is due to a lack of a systemic view; hence, the outcomes of these studies could be in fact synthesized to develop a comprehensive solution.

Similar to the discussion of M\&A issues, M\&A solutions can be structured into three categories: Business/Operations, HR/Organisational and IS/IT.

During M\&A-related transformations, one of the key business success factors is to maintain business and IS alignment. To maintain such alignment, Wijnhoven et. al. (2006) suggests using Henderson and Venkataraman's (1993) strategic alignment model. However, they only concentrate on the selection of IT-integration methods for a given type of merger and IT integration objectives. To explain the process of post-merger integration, $\mathrm{Mo}$ and Nemes (2009) suggest developing the metaphor of an architectural 'DNA' (biological DNA) inheritance. Using this 'DNA EA' concept, they explain post-merger integration as the inheritance of DNAs (process, knowledge, control, data, people and asset) of the involved organizations into the DNAs of the merged organization. Mo and Nemes 
(ibid.) propose a solution methodology to implement post-merger integration by treating six DNA components separately; however, details of how to integrate those six DNAs are not provided.

Post-merger integration planning needs to consider the level of integration required: Vernadat (2007) suggests an categorization framework, based on the targeted level of interoperability. According to Vernadat (ibid. p139) for Coordination a Business level, for Co-operation an Application level, and for interoperable Communication a Physical System level integration is required. This model can help plan the expected level of interoperability and required level of integration.

Most researchers agree that $\mathrm{HR}$ issues are complex to resolve and have high impact on the end result of M\&As deals. The majority of HR issues are caused by the anxiety and low degree of bottom-up participation and involvement in the transformation process, consequently Rodriguez (2008) highlights the critical importance of top-down communication and bottom-up participation during M\&As. To address other HR issues, Schuler and Jackson (2001) suggest a three-stage HR integration model (precombination, combination and solidification). Their model covers major HR activities, strategies and planning for successful post-merger integration. They consider strategic HR concerns such as cutoffs, retentions, promotions and communication during M\&A transformations. Although some of the practitioners and researchers suggest the idea of unfreeze-transform-freeze as a solution; such simplistic concepts are highly criticised for not considering emergent issues (such as those brought about by the dynamicity and complexity of the change process, inabilities of change leaders and inefficiencies of micro level linear planning (Lauser, 2009)) and also for the unrealistic view of human resources as a commodity by the HR community (Dooreward and Benschop, 2003). Recent research in HR also advocates the strategic role of $\mathrm{HR}$ in enterprise-wide change endeavours (Bhaskar, 2012). Unfortunately, the impact of the decisions made to resolve HR concerns on IS and Business integration is not addressed in the proposed model (ibid.); thus, the validity of these suggestions remains unclear.

Although the planning of post-merger integration is considered vital and complex, the need for careful planning is still often neglected during the premerger phase (Larsen, 2005). Larsen (ibid.) suggests a model to create an ICT vision for the M\&A; such a model enables considering ICT integration during pre-merger planning. Bannert and Tschirky (2004) suggest an integration planning model for IT intensive M\&As. According to their explanation, technology integration should cover various IS components such as enterprise applications, platforms (including operating systems, communication, security, and database systems).

Giacomazzi, Panella, Pernici and Sansoi (1997) suggest a model of post-merger IS integration and provide a list of options available (Total Integration, Partial Integration, No Integration and Transition) for a given computer architecture and software architecture. In addition, they provide a descriptive model in order to explain how to implement each of the IS integration options. With the wide use of ERP systems, it is also necessary to develop an Application Integration Strategy; Eckert, Freitag, Matthes, Roth and Schilz (2012) provide a methodology for this, based on the type of M\&As and the aimed synergy. To better understand postmerger integration, Mehta and Hirschheim (2007) suggest an IS Integration decision making framework that to guide decisions for Post-merger integration. The framework is based on the strategic alignment model (Hirschheim and Sabherwal, as cited in Mehta and Hirschheim (2007)).

Ross, Weill and Robertson (2006) suggest that the level of business process integration (sharing data across parts of the organization, and therefore requiring business data integration) and the level of business process standardization (use of uniform business processes across the organization) can decide an operating model for the organization. They (ibid, pages 29-39) suggest a framework to differentiate four operating models, based on the level of business process integration and business process standardization. It appears that an operating model can be decided based on the choices made for business process integration and standardization, technology- and organizational integration, and making strategic choices based on this model can guide further M\&A implementation.

It seems that none of the solutions outlined above are able to address all the issues or to consider the impact on and/or relationships with the other issues. In addition, the models and theories noted above focus on individual aspects of M\&A, and results documented in the current literature need to be synthesized in order to adopt a comprehensive approach for solving M\&A issues in concert.

\subsection{Gaps in Theory and Practice}

In their review of the last 30 years of M\&A literature, Cartwright and Schoenberg (2006) found that $M \& A$ research is still incomplete. 
Based on our own survey, major gaps in M\&As research can be summarised as follows:

- Lack of a multi-disciplinary approach (Cartwright and Schoenberg, 2006, pg. 5);

- "the study of M\&A desperately needs a new perspective and a new framework for analysis" (Epstein, 2005, pg. 37);

- Need to consider the emergent nature of M\&A (Lauser, 2009);

- Lack of agile, flexible, quick-responsive framework suitable to M\&As' complexity (Mo \& Nemes, 2009);

- Lack of Systems approach (Mo and Nemes, 2009, pg. 4; Larsen, 2005; DiGeorgio, 2002), whereupon a systems approach would provide a unified framework that able to represent the range of problems that arise from the transformation of two systems into a single system

\section{THE SYNTHESIZED SOLUTION: M\&A PREPAREDNESS BUILDING}

From the above discussion it is clear that a systems approach is required to address the high failure rate of M\&As. It is unlikely that once an M\&A deal is on the horizon there will be sufficient time to perform groundwork and planning for post-merger integration to address relevant problems.

Therefore, the management of an organization should consider preparing the enterprise for such types of transformation before any concrete $M \& A$ deal is considered. This is to ensure that the organisation has the right capabilities and systemic properties (such as flexibility, agility, etc.) required to perform post-merger integration tasks. We therefore recommend a preparedness building program for organisations that want to consider such strategic moves as future options.

The discussion below presents the proposed timing of preparedness building (in contrast to the conventional view of the M\&A process) and then outlines the actual process of preparedness building.

\subsection{The M\&A Process}

Based on the discussion of M\&A problems, it is evident that individual solutions addressing issues independently are neither feasible nor optimal. Unfortunately, at the time an actual merger or acquisition is considered, there is typically not enough time to spend on comprehensive planning of post-merger integration. Thus, there seems to be a contradiction between having to make fast decisions to seize the opportunity and the need to perform comprehensive planning.

To solve the above problem (as described in detail in Vaniya (2011) and shown in Figure 1), we could consider desirable life trajectories of an enterprise prior to having actual merger or acquisition plans. Therefore, instead of using the conventional view of a three-stage M\&A process (Pre-merger, Merger and Post-merger) we introduce an additional $M \& A$ preparedness building stage. During this stage, some groundwork can be completed to better position the enterprise, so that by the time an opportunity is sighted, the enterprise is in the position to quickly make necessary decisions and finalise comprehensive integration planning. We call these activities 'preparedness building'. They aim to achieve the acquisition of important systemic (system level) properties such as flexibility, agility and interoperability as enablers of future transformations



Figure 1: Preparedness Building in M\&A Process. 


\subsection{The M\&A Preparedness Building Methodology and the Transformation Process}

In the following, we shall demonstrate how to conduct the Preparedness Building stage shown in Fig. 1. For this purpose we employ a high-level three-step reference methodology Vaniya and Bernus (2012), as follows:

- Step 1: Identify Enterprise entities;

- Step 2: Show the role of each entity in the preparedness building transformation;

- Step 3: Demonstrate the relative sequence of transformational activities, using life history diagrams.

Step 1 identifies the participating enterprise entities. They can be existing entities (for example existing Management team, business units, affected business processes, IT infrastructure, etc.) contributing to building preparedness or can be additional entities required in building preparedness (for example Preparedness Building Strategic Program, Gap Analysis Project, Business-, HR- and IS- Preparedness Building Projects, etc., or even strategic partners).

Step 2 shows the role of each entity in the preparedness building transformation. Various graphical models can be used for this particular step; we have chosen the so-called 'dynamic business models' proposed by the IFIP-IFAC Task Force
(1999) showing the role of each entity in other entities' lifecycle phases.

Step 3 attempts to demonstrate the relative sequence of transformation activities. This step follows the previously identified roles of each of the entities; based on those roles, we first identify activities to match entities' responsibilities and then we establish their relative sequence using so-called 'Life History Diagrams' (see section 5.3).

Note that MAPBM aims to serve as a reference model, with the details and approaches of each step being adapted to meet the specific business needs, management decisions and current business scenarios.

\section{CASE STUDY: THE MERGER OF TWO TERTIARY STUDY INSTITUTIONS}

\subsection{Background}

Faculty $\mathrm{F}$ within university $\mathrm{U}$ contained several schools, with schools A and B having the same profile. School A is based at two campuses situated at locations L1 and L2, while school B is based at a single campus, situated at location L3 (as shown in the AS-IS state, see Figure 2). Historically, the schools have evolved in an independent manner, reflecting the local specific educational needs and
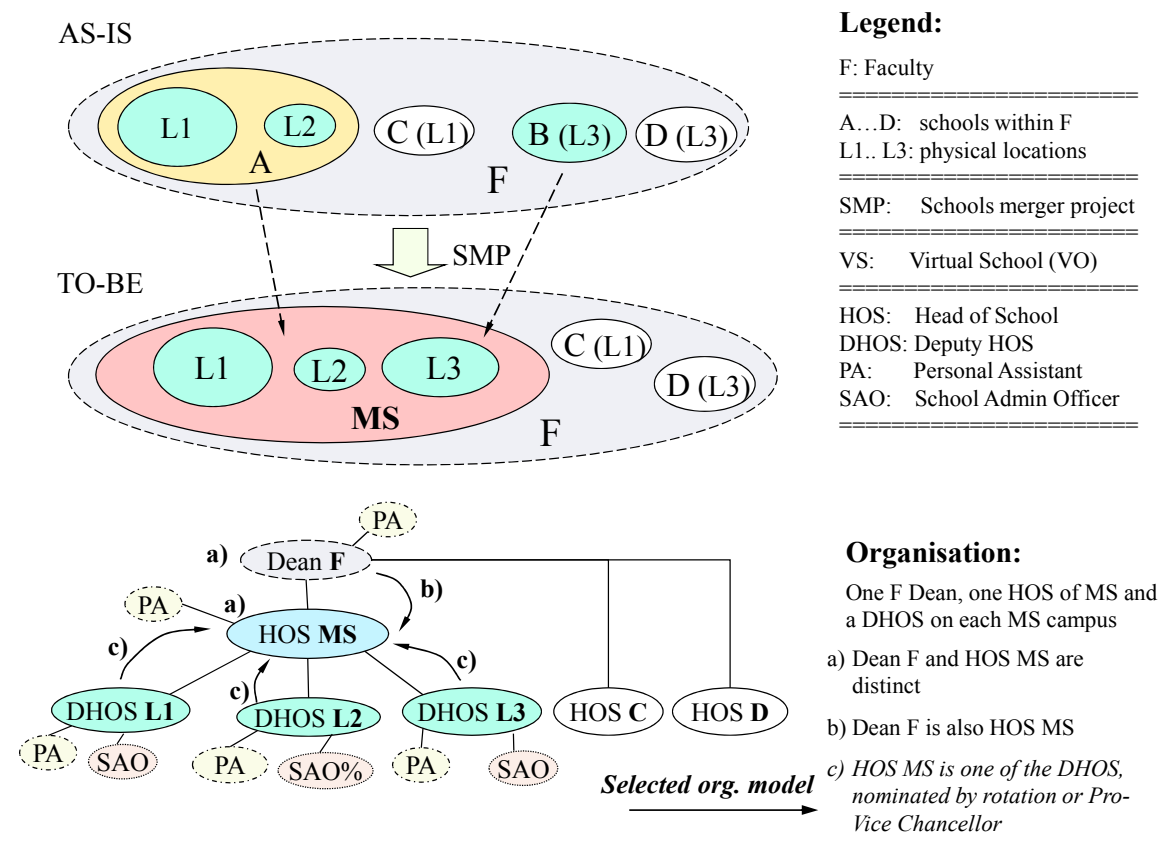

Figure 2: Rich picture of AS-IS and possible TO-BE states (incl. organisational scenarios). 
demographics. This has led to different organisational cultures, $\mathrm{HR}$ and financial management approaches. For example, school B enjoyed a large international student intake providing funds that supported heavy reliance on sessional (contract) staff for teaching and wide availability of discretionary funds. In contrast, staff in school A had a larger teaching load and had less funds available due to a smaller student intake.

Staff profile level between schools was significantly different (i.e. less high-level positions at school B). Course curriculums also evolved separately in the two schools, with similarly named courses containing significantly different material.

Thus, although of the same profile, and belonging to the same $\mathrm{F}$ and $\mathrm{U}$, schools $\mathrm{A}$ and $\mathrm{B}$ were confronted with a lack of consistency in their profiles, policies, services and resources. This situation caused additional costs in student administration and course / program design / maintenance, unnecessary financial losses as well as staff perceptions of unequal academic and professional standing between campuses, all of which were detrimental to the entire faculty.

Therefore, the management of $U$ and $F$ have mandated that the problems previously described must be resolved and have defined the goals of schools A and B becoming consistent in their products and resources strategy, eliminating internal competition for students and being subject to a unique resource management approach. As a solution, it has been proposed that the schools should merge into a single, multi-campus Merged School (MS in the 'TO-BE' state in Fig. 2). The unified MS management and policies would promote consistency in the strategy regarding the products delivered and the resources allocated to its campuses.

After further consultation, the Heads of the participating Schools have set an organisational goal allowing the individual campuses to retain a significant part of their internal decisional and organisational structure after the merger, perhaps with an added higher layer of an overall governance structure. This structure was supported by the HR department as the simplest to implement and least painful transition-wise.

From the point of view of Information Services, the proposed merger presented the opportunity to set the goal to unify and streamline software and hardware deployments across campuses.

The business aspect of the merger goals concerned the elimination of internal competition (with the potential of increased enrolments and income) and a unique merged school image that was more attractive and less confusing to the national and international prospective market.

\subsection{The Results}

The Merged School Project has succeeded, albeit with some difficulties. The decisional, functional, information, resources and organisational models created during the merger have helped significantly to understand the present situation and to select an optimal future state. The use of languages easy to understand and able to manage complexity has resulted in stakeholder buy-in for the project and middle-management consensus on the essential aspect of the future Merged School.

Unfortunately however, most modelling and mappings (including the pre-merger AS-IS situation!) occurred during the merger project rather than before; thus, there was insufficient time to achieve appropriate detail modelling. This has led to the 'devil in the detail' situation: the human resources allocated to accomplish the merger and post-merger integration tasks were unable to do so appropriately due to the lack of proper understanding of what needed to be done.

In addition to their inappropriate granularity, the available models were only partially applied. For example, an organisational model showing changes in roles and decisional framework in the transition from the AS-IS to the TO-BE states was implemented only at the top layer due to the lack of time and proper preparation. As a result, the new Head of the Merged School had to spend significant amounts of time 'putting out fires' (finding short term solutions to re-occurring product / resources imbalances). Thus, unfortunately the interventionist and turbulence issues outlined in the pre-merger (AS-IS) organisational and decisional models were not effectively addressed.

Staff consultation has taken place; however, a significant amount of feedback never translated into changes to the proposed organisational model. This has reduced the level of acceptance among staff.

Importantly, the detailed process modelling was never completed and as such the implementation went ahead without detailed models and guidance, in a 'cold turkey' manner (i.e. overnight changeover) resulting in a state of confusion as to "who does what, now' lasting several months and affecting both staff and clients (students) In other words, there was little attention given to post-merger integration.

On the positive side, the Merged School did achieve a unique image, and in time reached an 
increased level of integration and consistency across campuses and more efficient resource management.

\subsection{Lessons Learned}

To sum up, there were a few lessons learned from the successes and short-term failures of this project. To start with, such a project needs an enduring 'champion' in an authoritative management position in order to back the project for its entire duration.

The modelling processes involved in M\&As must start early; ideally, a reference model repository should be built in advance and constantly enriched based on each merger post-mortem. Some human-specific processes (such as trust building, negotiations etc) cannot be rushed and thus, preparedness is key.

The detailed design and implementation phases of M\&As must be properly planned for and performed. Especially when organisational changes involving human aspect are involved, suitable detail must be provided so that people understand their new/changed roles. Feedback from stakeholders must be gathered, refined and incorporated in the final models, being crucial in post-merger integration.

\section{APPLYING THE PREPAREDNESS BUILDING METHODOLOGY}

Preparedness can be built for announced and potential M\&As. Here the merger partners were known, therefore this is a case of preparedness building for an announced merger.

Out of the three categories of issues (as outlined in section 2.1), major issues presented by the case study are Business and Management and Human Resource issues. IS / IT issues are limited to the challenges in achieving consistency in the way IS and IT are managed for the involved schools. Therefore, the aim of preparedness building could be the following:

- Identify obstacles to the transformation and implement appropriate preventive actions;

- Plan for post-merger integration based on the expected outcomes;

- Prepare a Post-Merger Integration (PMI) Plan and an Integration Strategy

- Involve key stakeholders (both schools' management, administration and academic staff) in the preparedness building activities

\subsection{Step 1: Identify Enterprise Entities}

From the discussion of the case study, the entities affected by preparedness building are the Heads of Schools (HOSs), academic and administration Staff, students, services, technical infrastructure and Information Services.

Preparedness building requires a strategic program typically governing several projects covering the proposed organisation-wide change, running for extended periods. A possible list of the program and projects involved is: a Preparedness Building Strategic Program (PBSP), a Business Preparedness Building Project (BPBP) and a HR Preparedness Building Project (HRPBP). In practice, the list of enterprise entities is negotiated between the project / program managers, key stakeholders and the relevant governance body.

\subsection{Step 2: Show the Role of each Entity in Preparedness Building Transformation}

The next step is to show how the identified entities will interact with each other to conduct the preparedness building transformation. This can be achieved by developing so-called 'dynamic business models'; the models applicable to the case study are shown in Fig. 3 and Fig. 4. It should be noted that, in these models, each 'relationship' is considered a contribution of an entity to another entity's lifecycle activities; According to ISO 15704, for each relationship the acting entities would typically use available reference / partial models to create the design solution for their particular target entity (see Appendix A).

Figure 3 shows the role of existing entities in establishing the required program and project entities. The management at the University and Faculty levels in consultation with HOSs of schools $\mathrm{A}$ and $\mathrm{B}$ decide to prepare for upcoming M\&As. Therefore they decide, identify, conceptualise and specify the requirements (mandate) of the Preparedness Building Strategic Program (PBSP), structure a strategic management team, and provide the basis for a master plan of the program (Relationship 1). Potentially, PBSP management can be made up of both HOSs, with one of them being the Program Manager, and key staff of all two schools in addition to members from University and Faculty. From here on, PBSP management is responsible for the design and implementation of PBSP. In the detailed design, program management designs the program team, and plans their tasks. This 
planning follows a project-based design to develop the detailed design of the program (i.e. to identify projects, their tasks and prepare a mandate for each project) (Relationship 3); in doing so, the Program Management Team also seeks the guidance of all staff of two schools (Relationship 2).

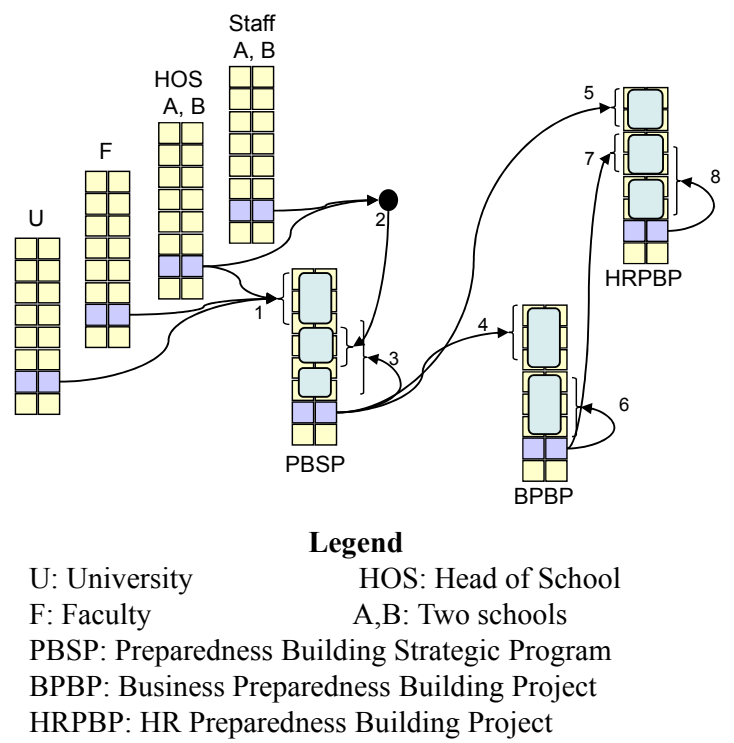

Figure 3: Establishment of Preparedness Building Program \& Projects.

For the identified change activities, the PBSP defines two separate projects which can be called BPBP (Business-) and HRPBP (HR-) Preparedness Building Projects with BPBP being the governing project to maintain the strategic alignment during the transformation. The PBSP program team identifies conceptualises and specifies the mandate of BPBP (Relationship 4) but only identifies and conceptualises HRPBP (Relationships 5). This is because HRPBP's mandate will have to be defined by the BPBP (Relationships 7). Relationships 6 and 8 represent the self-designing and re-engineering capabilities of BPBP and HRPBP respectively.

Figure 4 shows the preparedness building changes initiated by PBSP, BPBP and HRPBP. The role of PBSP is to govern and monitor the progress of M\&A preparedness building, and the operations of BPBP as well as HRPBP. BPBP is responsible for planning and implementing preparedness building (key tasks: Gap Analysis, Requirement Specifications, preparing mandates for HRPBP, plan for business processes \& product integration, improve consistency in current operation). The role of HRPBP is critical for our case, as HRPBP would be responsible for preparing staff for the merger, achieving consistent organisational structure and HR management practices across the campuses.

Starting with the operation of BPBP, the BPBP identifies necessary changes at the HOS level to achieve consistency in managing schools, their staff and products (Relationship 1). HOSs are the leaders for their respective schools and they are also part of the PBSP team, therefore it is necessary to first implement changes at their level. Such initiatives reflect that preparedness building has executive management's commitment and support.

Similarly, the HRPBP, with the help of BPBP, suggest equivalent changes for the staff such as preparing staff for future organisational structure (Relationship 2). Key transformational activities may involve identifying and categorising roles that would become redundant, remain unchanged and any new roles required after the merger. This would also require changes into the staff structure and organisational processes. For example, for a course offered at multiple campuses we might need a new role such as Primary Course Convener supervising (existing) Campus Conveners. In addition these smaller teams must plan for possible changes into designs and structures of their respective courses and should come up with an integration plan for their respective courses/programs. To reflect such major changes into organisational structure, the schools also need to identify changes in current reporting mechanisms, communication methods, promotion arrangements. Another major task for HRPBP would be to plan, initiate and continuously foster the culture change. Cultural change would be critical for transforming two competitive teams into a collaborating one and prevent residual 'us and them' feelings that normally result unplanned/unsuccessful cultural integration. If needed, arrangements should be available to transition/support the students affected by the school merger (Relationship 3).

Staff of the two schools must make necessary changes to their products (Relationship 4). Based on guidelines from BPBP, major transformational activities are to analyse the designs of degrees, the structures and contents of courses, and plan for making the products consistent across the campuses.

To manage resources effectively, HOSs need to identify a way to manage and maintain resources in a unified way. Therefore they must identify and changes current resource arrangements (Rel'ship 5). Staff and HOSs of all schools must suggest changes to existing Technical Infrastructure and IT Applications/Services, particularly to support postmerger planning of integrating products. 


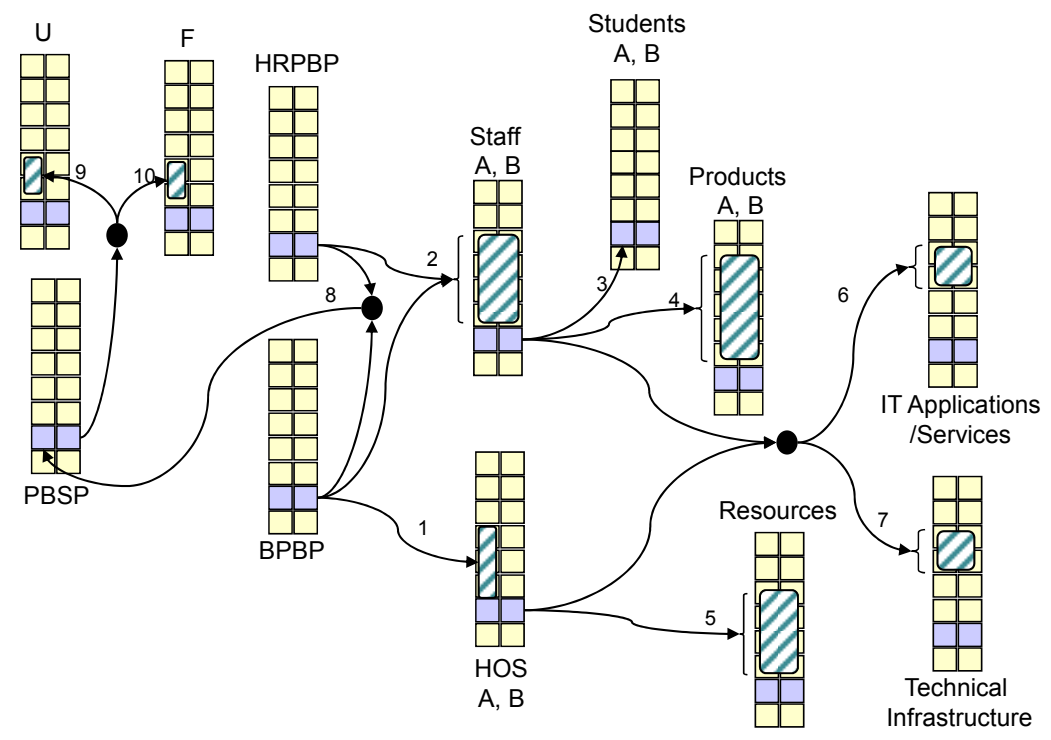

Figure 4: Transformational Initiatives in Building Preparedness.

After PMI, support is needed for cross-campus communication and resources sharing. Such changes support the organisations in preserving the established M\&A Preparedness (Rel'ship 6 \& 7).

While making all the precautionary changes in the current arrangements, BPBP and HRPBP teams may identify relevant changes at the Faculty and University levels to maintain the strategic alignment. Such changes could be in the current policies and principles, reporting systems, management and controlling procedures. As noted by Mcdonald, Coulthard and Lange (2005) such changes in existing strategy are required for an effective $M \& A$ implementation. Therefore BPBP and HRPBP can inform the PBSP team about such changes (Relationship 8). In turn PBSP team recommends those changes to the Faculty and University Management (Relationships 9 \& 10).

Changes will then be proposed to U\&F, which may approve (or not); nevertheless, they must reach consensus that can maintain strategic alignment between M\&A strategy and corporate goals, and that of the Business, HR and IS strategy for M\&A Preparedness building.

In this discussion we have argued that a possible Preparedness Building Exercise can be planned to achieve basic systemic properties/design properties, so that change can become a natural and dynamic exercise rather than the occasional forceful imposition on the organisation. In this case study, there were no explicit shared representations of processes (in a formal enough manner), which would have allowed to define the new processes needed by the merged organisation. Preparedness building would have entailed the development of explicit and shared process models. As no resources were allocated to perform the necessary modelling even after the merger, the distributed operation of MS was affected by process inefficiencies.

\subsection{Step 3: Demonstrate Relative Sequence of Transformational Activities}

Finally, once the mandate of preparedness building transformation is finalised, it is important to identify the detailed activities that must be performed as well as by whom and when.

For this particular step we have used so-called 'life history' diagrams (c.f. ISO 15704), that show entities and their lifecycle phases on a vertical axis and time on the horizontal axis. Such diagrams show major milestones and then may become the basis for project management charts (such as Gantt). As explained in Vaniya and Bernus (2012), MAPBM is developed based on EA concepts using GERAM (IFIP-IFAC Task Force, 1999, ISO/IEC, 2005). Figure 5 presents an extract from the set of life history diagrams developed for the case study. In such diagrams we can also show the concurrent activities such as activity 3 as shown in Fig. 5. 


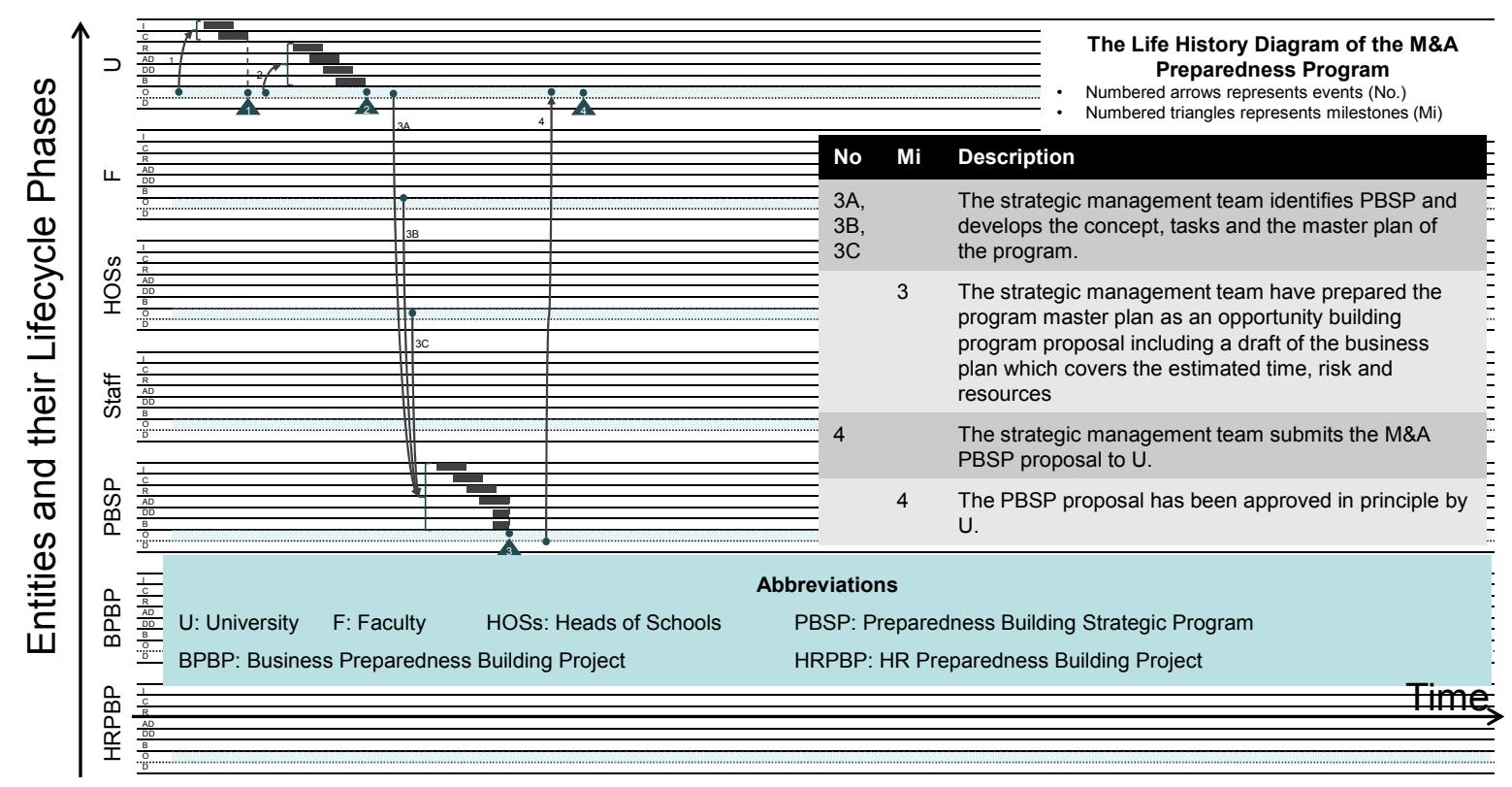

Figure 5: An example of Life History Diagram for Preparedness Building.

\section{CONCLUSIONS AND FUTURE RESEARCH}

The paper has reviewed three categories of issues that are commonly considered the reason for high failure rates for M\&As. Using a systems view of enterprise transformation (based on an EA approach), we have identified a contradiction between the need to address post-merger integration planning in detail and the usual time pressure when an M\&A deal is considered.

Our main contribution is that we proposed a solution called 'preparedness building', that allows enterprises to consider M\&As as strategic possibility (even if not actual yet), and determine what systemic changes are necessary in the three categories (business, IS / IT and HR), so that the organisation can develop flexibility in these areas. To achieve such preparedness building requires strategic initiative and organisational change. Given the complexity of this transformation we used an Enterprise Architecture approach to demonstrate how a simultaneous transformation of business, HR and IS/IT aspects can be orchestrated to achieve M\&A preparedness as a systemic property of the enterprise. We have also discussed a case study, and what areas could have been addressed by the proposed preparedness building methodology, so as to improve the speed and efficiency of the Merger that was eventually completed.
The proposed M\&A Preparedness Building Methodology could be evolved into a Preparedness Building package aiming to improve M\&A success rate by addressing the root causes of issues, so that an enterprise is ready for M\&As and similar enterprise-wide change endeavours. It is also important to have a mechanism to determine whether the organisation is ready for the desired type of M\&A. Based on such a determination, a prescriptive list of activities can be provided as a roadmap towards building preparedness for the desired type of M\&A. Therefore, research is in progress to develop the checklist of key M\&A issues and their solutions, define the state of M\&A Preparedness in terms of systemic properties and develop an optimal list of M\&A Preparedness Building Activities for different types of M\&As.

For the above goals, a mixed-method research will involve an international survey and follow-up semi-formal interviews to consider industry response to the M\&A Preparedness Building Methodology development. The results of this research will also be verified by an expert panel consisting of M\&A practitioners and researchers.

\section{REFERENCES}

Alaranta, M. and Henningsson, S. (2008). An approach to analyzing and planning post-merger IS integration: Insights from two field studies. Information Systems 
Frontiers, 10(3), 307-319,

Bannert, V. and Tschirky, H. (2004). Integration planning for technology intensive acquisitions. $R \& D$ Management, 34(5), 481-494.

Baro, G. A., Chakrabarti, A. and Deek, F. (2008). Organizational and Informational System Factors in Post-Merger Technology Integration. AMCIS 2008 Proceedings, Paper 359, http://aisel.aisnet.org/ amcis2008/359.

Bhaskar A. U. (2012). HR as business partner during mergers and acquisitions: The key to success is to get involved early. Human Resources Management International Digest, 20(2), 22-23,

Cartwright, S. and Schoenberg, R. (2006). Thirty years of mergers and acquisitions research: Recent advances and future opportunities. British Journal of Management, 17(S1-S5), 1-5.

Chatterjee, S. (2009). The Keys to Successful Acquisition Programmes. Long Range Planning, 42(2), 137-163,

DiGeorgio, R. (2002). Making mergers and acquisitions work: What we know and don't know - Part I. Journal of Change Management, 3(2), 134-148.

Doorewaard, H. and Benschop, Y. (2003). HRM and organizational change: an emotional endeavor. $J$ of Organizational Change Management, 16(3), 272-286,

Eckert, M., Freitag, A., Matthes, F., Roth, S. \& Schilz, C. (2012). Decision support for selecting an application landscape integration strategy in mergers and acquisition. ECIS 2012 Proceedings, Paper 88, http://aisel.aisnet.org/ecis2012/88.

Epstein, M. J. (2004). The Drivers of Success in PostMerger Integration. Organizational Dynamics, 33(2), 174-189, doi:10.1016/j.orgdyn.2004.01.005.

Epstein, M. J. (2005). The determinants and evaluation of merger success. Business Horizons, 48, 37-46

Giacomazzi, F., Panella, C., Pernici, B. and Sansoi, M. (1997). Information Systems integration in mergers and acquisitions: A normative model. Information \& Management, 32, 289-302.

Henderson, J. and Venkatraman, N. (1993). Strategic alignment: Leveraging information technology for transforming organization. IBM Systems Journal, 32(1), 4-16.

Hwang, M. (2004). Integrating Enterprise Systems in Mergers and Acquisitions. AMCIS 2004 Proceedings, Paper 12, http://aisel.aisnet.org/amcis2004/12.

IFIP-IFAC Task Force. (1999). The generalised enterprise reference architecture and methodology (GERAM). Retrieved May 1, 2010, from http:// www.ict.griffith.edu.au/ bernus.

ISO/IEC. (2005) 'Annex A: GERAM'. In ISO/IS 15704:2000/Amd1:2005: Industrial automation systems - Requirements for enterprise-reference architectures and methodologies,

ISO/IEC. (2007) ISO/IEC 42010:2007: Recommended Practice for Architecture Description of Soft-wareIntensive Systems,

Kumar, R. (2009). Post-merger corporate performance: an Indian perspective. Management Research News 32(2), 145-157.
Larsen, M. H. (2005). ICT Integration in an M\&A Process. PACIS 2005 Proceedings, Paper 95, http://aisel.aisnet.org/pacis2005/95.

Lauser, B. (2009). Post-merger integration and change processes from a complexity perspective. Baltic Journal of Management, 5(1), 6-27

Mcdonald, J., Coulthard, M. and Lange, P. D. (2005). Planning for a Successful Merger or Acquisition: Lessons from an Australian Study. Journal of Global Business and Technology, 1(2), 1-11.

Mehta, M. and Hirschheim, R. (2007). Strategic Alignment In Mergers And Acquisitions: Theorizing IS Integration Decision making. Journal of the Association for Information Systems 8(3), 143-174.

Mo, J. P. T., and Nemes, L. 2009. Issues in Using Enterprise Architecture for Mergers and Acquisitions (235-262). In G. Doucet, J. Gotze, P. Saha, \& S. Bernard (Eds.) Coherency Management. Author House, Bloomington Indiana.

Rodriguez, A. (2008). Mergers and Acquisitions in the Banking Industry: The Human Factor. Organization Development Journal, 26(2), 63-74.

Ross, J.W., Weill, P. and Robertson, D.C. (2006). Enterprise architecture as strategy: Creating a foundation for business execution. Harvard Business School Press, Boston, Massachusetts.

Schuler, R. and Jackson, S. (2001). HR issues and activities in mergers and acquisitions. European Management Journal, 19(3), 239-253,

Stylianou, A. C., Jeffries, C. J. and Robbins, S. S. (1996). Corporate mergers and the problems of IS integration. Information \& Management, 31, 203-213

Vaniya, N. (2011). Building Preparedness for M\&As: The role of EA practice. Retrieved September 25, 2011 from www.ict.griffith.edu.au/cearm/docs/pubs/vaniya2011a.pdf

Vaniya, N. \& Bernus, P. (2012). Strategic Planning to build Transformational Preparedness: An Application of Enterprise Architecture Practice. ACIS 2012 Proceedings, http://dro.deakin.edu.au/view/DU:3004 9142.

Vernadat, F.B. (2007). Interoperable enterprise systems: Principles, concepts, and methods. Annual Reviews in Control, 31, 137-145

Walsh, J. P. (1989). Doing a deal: Merger and acquisition negotiations and their impact upon target company top management turnover. Strategic Management Journal, $10,307-322$

Walter, I. (2004). Mergers and acquisitions in banking and finance. Oxford University Press, New York.

Wijnhoven, F., Spil, T., Stegwee, R. and Fa, R.T.A. (2006). Post-merger IT integration strategies: An IT alignment perspective. Journal of Strategic Information Systems, 15, 5-28. 


\section{APPENDIX A}

\section{Some Basic Ea Concepts}

Some concepts of Enterprise Architecture (EA) as defined in GERAM (a standardized generalization of EA framework concepts IFIP-IFAC Task Force (1999) and ISO 15704), are explained below.

Enterprise Entities: GERAM defines the concept of Enterprise Entities (EEs) through exemplification. EEs are managed / controlled systems that have a mandate or purpose. One can categorise entities according to how they contribute to the life of other entities. For example, Strategic Enterprise Management Entities may create Change Programmes, Change Programmes may create Change Projects, these in turn may create or change Business Units, which in turn may change or create Products etc. (GERAM calls these 'recursive' type definitions).

Lifecycle: GERAM defines the concept of life cycle as an ordered list of activity types (or functions) that consider an entity on various levels of functional abstraction. (I.e. the ordering is based on one function's output constraining the next function's input). This ordering is not temporal (because feedbacks exist among life cycle activities). 'Lifecycle phases', or 'life cycle activity types' associated with the life of an entity shown in Figure.
Life History: The life history of an entity is the representation in time of life cycle activity instances carried out on the particular entity during its entire life span (IFIP-IFAC Task Force (1999) and ISO 15704). In a sense by building the life history diagrams of all involved entities in an organizational change effort, one can describe all required organizational processes and operations to carry out that organizational change. Interestingly such life history diagrams can help to anticipate and systematize the operational structures of processes; for example, identification of all involved processes, prioritization of those processes, identification of sequence of processes, identification of parallel processes, etc. At any moment in time multiple activity instances may be active on the same entity, in parallel.

Viewpoints: Viewpoints (originally called views in GERAM 1.6.3) are categorized in GERAM's GERA 'modelling framework', and represent types of models which may be created at various levels of abstraction to answer various concerns about the Enterprise Entity. These types of models may be categorized according to Model Content, Entity Purpose, Entity Implementation and Physical Manifestation. The following discussion briefly explains these four types.

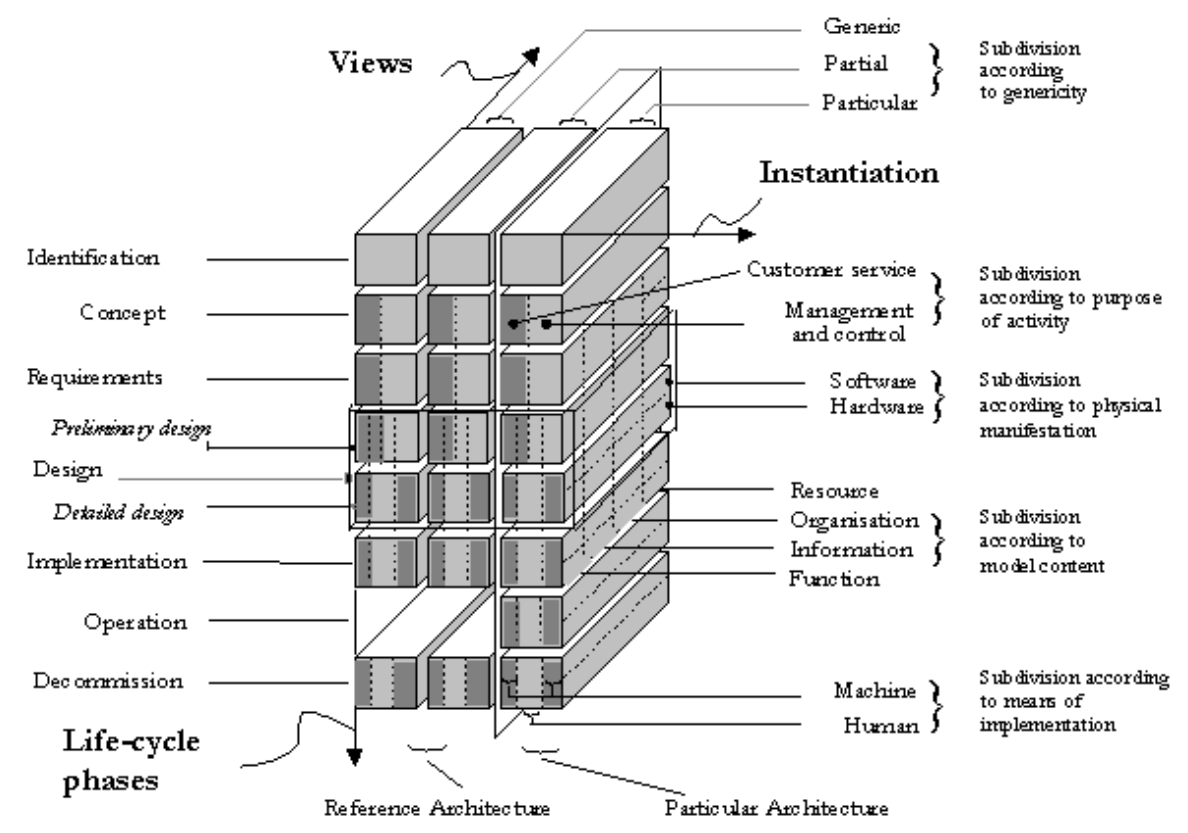

Figure 6: GERA Modelling Framework with Lifecycle Phases, Viewpoints.

Source: (IFIP-IFAC Task Force (1999) and ISO 15704) 